\title{
Risk Factors of Cardiovascular Diseases in HIV/AIDS Patients on HAART
}

\author{
Dickson Shey Nsagha", ${ }^{*}$, Jules Clement Nguedia Assob ${ }^{2}$, Anna Longdoh Njunda ${ }^{2}$, \\ Elvis Asangbeng Tanue ${ }^{2}$, Odette Dzemo Kibu ${ }^{2}$, Charlotte Wenze Ayima ${ }^{2}$ and \\ Marcelin Ngowe Ngowe ${ }^{3}$
}

\author{
${ }^{I}$ Department of Public Health and Hygiene, Faculty of Health Sciences, University of Buea, P.O Box 63, Buea, \\ Cameroon \\ ${ }^{2}$ Department of Medical Laboratory Sciences, Faculty of Health Sciences, University of Buea, P.O Box 63, Buea, \\ Cameroon \\ ${ }^{3}$ Department of Surgery, Obstetrics and Gynaecology, Faculty of Health Sciences, University of Buea, P.O Box 63, \\ Buea, Cameroon
}

\begin{abstract}
Background: The introduction and widespread use of combination antiretroviral therapy referred to as highly active antiretroviral therapy (HAART) in the mid 1990's, has led HIV-infected individuals to experience a dramatic decline in immunodeficiency-related events and death. There is growing concern on metabolic complications associated with HIV and HAART which may increase cardiovascular risk and disease. The aim of this study was to investigate the cardiovascular risk profile of HIV/AIDS patients receiving HAART and those not receiving HAART at HIV/AIDS treatment centres in the South West Region of Cameroon.
\end{abstract}

\begin{abstract}
Methods: Consenting participants, who had been receiving HAART, were compared with HAART naive participants. A questionnaire was administered; anthropometric and blood pressure measurements were recorded under standard conditions. Blood samples were obtained for the determination of plasma glucose and lipid levels.
\end{abstract}

Results: Two hundred and fifteen participants were recruited, $160(74.4 \%)$ were on HAART and $55(25.6 \%)$ were HAART naive. Among the individual lipid abnormalities, increased total cholesterol was the most prevalent $(40.0 \%)$. Participants on HAART were significantly about 8 times at risk of developing hypercholesterolemia when compared to the HAART inexperienced group (OR 8.17; 95\% CI: 3.31-20.14; $\mathrm{P}<0.001$ ). Hypertension had a prevalence of $25.6 \%$ (95\% CI: $15.3 \%-35.9 \%)$ and was about 2 times significantly higher in the HAART treated than the HAART untreated group $(\mathrm{p}=0.033)$. The prevalence of low HDL-c was significantly higher in males $(24.1 \%)$ compared to females $(11.2 \%)$ $(\mathrm{p}=0.0196)$. Many females $(27.3 \%)$ were obese compared to males $(7.4 \%)(p=0.0043)$. HAART use and treatment duration of more than five years were significantly associated with higher prevalence of CVD risk factors.

Conclusion: HAART treatment was associated with significantly higher prevalence of hypercholesterolemia, increased LDL-c and hypertension, hence the risk of cardiovascular diseases.

Keywords: AIDS, Cardiovascular, Cameroon, dyslipidemia, HAART, HIV.

\section{BACKGROUND}

HIV and AIDS continue to be major public health problems in both developed and developing countries. Worldwide around 35.3 million people are living with HIV, with 32.1 million adults [1]. In 2012, an estimated 2.3 million new HIV cases occurred. The estimated number of AIDS related deaths in 2012 was estimated to be 1.6 million with adults being 1.4 million [1]. Sub-Sahara Africa (SSA) bears an inordinate burden of HIV and AIDS [1]. This burden is evident by the fact that more than two-thirds of the global 35.3 million people living with HIV/AIDS (PLWHA)

*Address correspondence to this author at the Department of Public Health and Hygiene, Faculty of Health Sciences, University of Buea, P.O Box 63, Buea, Cameroon; Tel: +237 677499429;

E-mails: nsaghads@hotmail.com or dsnsagha@gmail.com reside in SSA [1]. The estimated 1.2 million people who died of HIV-related illnesses in SSA in 2012 comprised $75 \%$ of the global total of 1.6 million deaths attributable to this epidemic [1]. The prevalence of HIV in Cameroon was estimated at $5.1 \%$ [2]. The prevalence varies between different regions with the North West Region having the highest prevalence of 8.7 and the South West Region occupying the fourth position with a prevalence of $8.0 \%$ [2]. By 2012 in Cameroon 600,000 people were estimated to be living with HIV and $46.7 \%$ or 280,000 were eligible for ART. Only 122783 people were currently receiving ART, which represented $45 \%$ of those in need in Cameroon [3].

As reported by WHO, approximately 9.7 million people in low- and middle income countries were receiving antiretroviral therapy by June 2012 [3]. The 300,000 people who were receiving ART in low-and middle-income countries in 2002 increased to 9.7 million in 2012. Between 
2002 and 2012, access to antiretroviral drugs in low- and middle-income countries rose 32-fold [3]. The introduction and widespread use of combination antiretroviral therapy (cART) referred to as highly active antiretroviral therapy (HAART) has led HIV-infected individuals to experience a dramatic decline in immunodeficiency-related events, including causes of death [4]. As a consequence, lifeexpectancy increased, which exposed them to the effects of aging itself, including the influence of environmental risk factors known to act in the general population and contributing to the occurrence of obesity, diabetes mellitus, and cardiovascular diseases [5].

The advent of HAART has been associated with a profound reduction in morbidity and mortality from HIV/AIDS [6]. However, several reports have documented increased prevalence of cardiovascular diseases (CVD) risk factors (such as obesity, elevated blood pressure, elevated blood sugar, hypertriglyceridemia, and low high-density lipoprotein cholesterol (HDL-c)) in both HAART-treated and HAART-naïve patients. The prevalence of metabolic syndrome in PLWHA from published studies varies from $10.1 \%$ to $45.4 \%$ [7-10]. Side effects and toxicities are associated with these highly effective therapies and there is growing concern that the metabolic complications associated with HIV and antiretroviral therapy may lead to an increased risk for cardiovascular diseases [7]. Several studies on cardiovascular diseases including coronary heart disease (CHD) risk factors among HIV/AIDS patients on HAART have been reported in the western literatures but there is scarcity of information on this subject in sub-Saharan Africa, which has the greatest HIV/AIDS burden and increasing access to HAART. Reports advocate that there is excess of CVDs among people living with HIV/AIDS [11-13] compared to HIV uninfected individuals. A similar pattern has been reported from studies in SSA [14,15] including Cameroon [16,17]. Failure to appreciate possible emerging problems of CVDs in PLWHA in SSA may mitigate the gains from antiretroviral therapy in this region with a high disease burden. Determination of these risk factors and appropriate intervention strategies where necessary is required and would allow for assessment of the impact of HAART on CVD risk. The aim of the present study was to assess risk factors for cardiovascular diseases in HIV/AIDS patients with no previously known history of CVD risk factors and the association with use of highly active antiretroviral therapies at treatment centres in Fako Division of the South West Region of Cameroon.

\section{METHODS}

\section{Study Setting and Participants}

This is part of the study conducted on "Cardiovascular disease risk factors among people living with HIV/AIDS: Association with Highly Active Antiretroviral Therapy" at the Faculty of Health Sciences, University of Buea, Cameroon. The other part of the study has been reported elsewhere [18]. This was a hospital-based cross-sectional study carried out at the HIV dedicated treatment centres of the Regional Hospitals of Buea and Limbe of the South West Region of Cameroon between March and August 2014. The study involved two groups of participants. The first group included HIV positive patients attending the HIV treatment centre of the hospital and had been receiving HAART for at least 6 months and reported by the treatment centres as nondefaulters. The second group was made up of individuals newly diagnosed with HIV infection and who were not yet receiving HAART because they were undergoing investigations before commencing HAART. We excluded patients less than 21 years of age, those on HAART for less than 6 months including defaulters of treatment regimen, pregnant and lactating women, those with documented hypertension, diabetes and dyslipidaemia before commencing HAART and those with any acute illness that required medical/surgical treatment or admission. Patients who met the inclusion criteria were consecutively recruited. HAART was defined as a combination of at least three classes of antiretroviral drugs namely protease inhibitors (PIs), non-nucleoside reverse transcriptase inhibitors (NNRTIs) and nucleoside reverse transcriptase inhibitors (NRTIs), one of which was a PI or an NNRTI or a combination of NRTI.

\section{Data Collection and Measurements}

The data collection has been described elsewhere [18]. Briefly, a structured questionnaires was used to collect data on the socio-demographic characteristics, patients' record were reviewed to obtain information on their current $\mathrm{CD}^{+} \mathrm{T}$ cell count, HIV and HAART status. Thorough physical examination was performed including measurement of blood pressure and anthropometric variables. Height was measured with a meter rule with the patients standing erect on a flat surface without shoes. Weight was recorded in kilograms using a standard weighing scale on a firm horizontal surface with patients wearing light clothing. Hypertension was defined as blood pressure equal to or greater than 140/90 $\mathrm{mmHg}$. Two blood pressure measurements were taken from each participant and the average calculated. Obesity was defined with the BMI $\geq 30.0 \mathrm{~kg} / \mathrm{m}^{2}$ using the World Health Organization (WHO) classification [19]. About $5 \mathrm{ml}$ of venous blood sample was collected from each participant after a 12 hour overnight fast and centrifuged at 2500 cycles/minute for 10 minutes, and then serum was obtained for lipid profiles measurements. Fasting blood sugar was assessed through enzymatic methods (INMESCO, GmbH (L-S 04/2009) for all participants and diabetes mellitus was defined using the American Diabetes Association (ADA) guidelines as fasting plasma glucose $\geq 126 \mathrm{mg} / \mathrm{dL}$ [20]. Lipid profile was assessed through enzymatic methods (INMESCO, GmbH (L-S 04/2009) for all participants and included total cholesterol (TC), high density lipoprotein cholesterol (HDL-c), low density lipoprotein-cholesterol (LDL-c) and triglycerides (TG). The TC/HDL-c ratio was also calculated. In accordance with the US National Cholesterol Education Program, Adult Treatment Panel III (NCEP-ATP III) guidelines, abnormal lipid profile was defined as TC $\geq 200 \mathrm{mg} / \mathrm{dl}$, HDL-c $<40 \mathrm{mg} / \mathrm{dl}$, LDL-c $\geq 130$ $\mathrm{mg} / \mathrm{dl}, \mathrm{TG} \geq 150 \mathrm{mg} / \mathrm{dl}$ and $\mathrm{TC} / \mathrm{HDL}-\mathrm{c}$ ratio $\geq 5[21]$

\section{Ethical Considerations}

Ethical Clearance was obtained from the Institutional Review Board of the Faculty of Health Sciences of the 
University of Buea (Reference number 2014-02-0193). Administrative authorization was obtained from the Regional Delegation of the Ministry of Public Health and the District Health Services. The purpose of the study and the role of the participants were well explained verbally and in the consent form and participation could only take place after the participant had read and signed the informed consent form voluntarily.

\section{Data Management and Analysis}

Questionnaires were cross-checked for consistency and the use of correct codes daily. Data entry was carried out on Microsoft excel 2010 (Microsoft Corporation Inc, USA). Statistical analysis was done using the Statistical Package for the Social Sciences (SPSS), version 20.0. Analysis of continuous variables was carried out using descriptive statistics and the Student's " $t$ " test. Categorical variables were analyzed using Chi-square $\left(\chi^{2}\right)$ test for statistical differences between the groups. The relationship between HAART and CVD risk profile was determined using logistic regression analysis. All p-values were two-tailed, and values less than 0.05 were considered to be statistically significant at $95 \%$ confidence level.

\section{RESULTS}

\section{Demographic Characteristics of the Study Population}

The participants consisted of $54(25.1 \%)$ males and 161 (74.9\%) females. Two groups of participants were recruited in the study. The first group comprised 160 (74.4\%) HIVinfected patients [36 (22.5\%) males, $124(77.5 \%)$ females], were currently receiving HAART treatment. The second group was made up of $55(25.6 \%) \mathrm{HIV}$-infected patients [18 (32.7\%) males, $37(67.3 \%)$ females], were HAART-naive. The ages ranged from 21-73 years with the mean age being $44.2 \pm 11.1$ years. The mean age of individuals who were on HAART was $44.7 \pm 10.7$ years while that of HAART naïve participants was $38.6 \pm 10.9$ years (Table 1 ).

HAART regimens were combinations of two nucleoside reverse transcriptase inhibitors and one non-nucleoside reverse transcriptase inhibitors (2NRTI and 1NNRTI) or 2NRTI and one protease inhibitor (2NRTI and 1PI). All participants on HAART were on a lamivudine (3TC) based backbone. HAART patients had been on treatment for a mean of $62.7( \pm 41.7)$ months. The number of patients on $\mathrm{AZT}+3 \mathrm{TC}+\mathrm{EFV}$, and $\mathrm{AZT}+3 \mathrm{TC}+\mathrm{NVP}$ regimens were 2 $(1.3 \%)$ and $80(50.0 \%)$ respectively, while those on $\mathrm{TDF}+3 \mathrm{TC}+\mathrm{EFV}, \mathrm{TDF}+3 \mathrm{TC}+\mathrm{NVP}$, and $\mathrm{TDF}+3 \mathrm{TC}+\mathrm{LPV} / \mathrm{r}$ regimens were $44(27.5 \%), 21(13.1 \%)$ and $13(8.1 \%)$ respectively. Zidovudine (AZT) based regimen constituted $82(51.3 \%)$ whereas tenofovir (TDF) based regimen constituted $78(48.8 \%)$. One hundred and one $(63.1 \%)$ patients were on nevirapine (NVP) as the third agent in the HAART, $46(28.8 \%)$ on efavirenz (EFV) and $13(8.1 \%)$ participants on lopinavir (LPV/r). The baseline clinical and biochemical parameters of the study participants are presented in Table $\mathbf{2}$.

\section{Cardiovascular Disease Risk Factors and HAART Status of the Study Population}

The proportions of cardiovascular disease risk factors in the 2 groups are shown in Table 3 . Among the individual lipid abnormalities, increased total cholesterol was the most prevalent $(40.0 \%, \quad 95 \%$ CI: $31.8 \%-48.2 \%)$. HAART experienced participants were significantly about 8 times at risk of developing hypercholesterolemia when compared to the HAART inexperienced group (OR 8.17; 95\% CI 3.3920.14; $\mathrm{P}<0.001$ ). Increased LDL-c was diagnosed in $29.3 \%$ of the participants with the risk of having increased LDL-c about 6 times higher in the HAART treated participants than in the HAART untreated participants and this was statistically significantly different (OR 5.69 ; $95 \%$ CI 2.15 15.06; $\mathrm{P}<0.001$ ). Hypertriglyceridemia was diagnosed in $19.5 \%$ (95\% CI: $8.3 \%-30.7 \%$ ) of the study participants and this was not significant influenced by the HAART status of the participants. Obesity was present in $22.3 \%$ (95\% CI: $11.5 \%-33.1 \%$ ) of the participants and was about 2 times higher in the HAART treated than HAART untreated group $(\mathrm{p}=0.113)$. Hypertension had a prevalence of $25.6 \%(95 \%$ CI: $15.3 \%-35.9 \%)$ and as a risk factor for CVD was about 2 times significantly higher in the HAART treated than the HAART untreated group $(\mathrm{p}=0.033)$.

The proportions of cardiovascular disease risk factors by gender are shown in Table 4. The prevalence of hypercholesterolemia was statistically significantly higher in the females $(45.3 \%)$ compared to the males $(24.1 \%)$ $(\mathrm{p}=0.0058)$. The prevalence of decreased HDL-c was significantly higher in males $(24.1 \%)$ compared to females $(11.2 \%) \quad(\mathrm{p}=0.0196)$. Also, many females $(27.3 \%)$ were found to be obese compared to males $(7.4 \%)(p=0.0043)$. Only male participants were current cigarette smokers (7.4\%), and also consumed alcohol on a regular basis $(40.7 \%)$ than females $(12.4 \%)(p<0.0001)$.

The CVD risk profile is higher in those on HAART treatments for more than five years (60 months) compared to other HAART treatment durations of less (Table 5).

\section{DISCUSSION}

Cardiovascular diseases are a widely recognized complication of HIV infection. Most of the traditional risk factors of CVDs present in the general population are also present among HIV-infected individuals. One of the strength of this cross-sectional study was its investigation of the longterm impact of HIV treatment with HAART-exposure durations infrequently observed in other developing countries where antiretroviral was available since the 1990's. The mean $\mathrm{CD}^{+} \mathrm{T}$ cell count was $421.5( \pm 279.9)$ cells/ $\mu$ l. We found that $\mathrm{CD} 4^{+} \mathrm{T}$ cell count in the HAART group was higher but not statistically significantly different from the HAART-naive group. This shows the effects of HAART in improving the immunological properties of the HIV treated participants. The atherogenic index for participants on HAART was found to be higher than that for the HAART 
Table 1. Demographic characteristics of the study population by HAART status.

\begin{tabular}{|c|c|c|c|c|}
\hline \multicolumn{2}{|l|}{ Variable } & $\begin{array}{c}\text { HAART Experienced Group }(\mathrm{n}=160) \\
\text { No }(\%)\end{array}$ & $\begin{array}{c}\text { HAART-Naïve Group }(\mathrm{n}=55) \\
\text { No }(\%)\end{array}$ & $\begin{array}{c}\text { Total } \\
\text { No }(\%)\end{array}$ \\
\hline \multirow{2}{*}{ Gender } & Male & $36(22.5)$ & $18(32.7)$ & $54(25.1)$ \\
\hline & Female & $124(77.5)$ & $37(67.3)$ & 161(74.9) \\
\hline \multirow{3}{*}{ Age (years) } & Mean \pm SD & $44.7(10.7)$ & $38.6(10.9)$ & $43.2(11.1)$ \\
\hline & $<45$ years & $85(53.1)$ & $41(74.5)$ & $126(58.6)$ \\
\hline & $\geq 45$ years & $75(46.9)$ & $14(25.5)$ & $89(41.4)$ \\
\hline \multirow{5}{*}{$\operatorname{BMI}\left(\mathrm{kg} / \mathrm{m}^{2}\right)$} & Mean \pm SD & $26.9(5.4)$ & $25.1(4.5)$ & $26.5(5.3)$ \\
\hline & $<18 \mathrm{~kg} / \mathrm{m}^{2}$ & $3(1.9)$ & $1(1.8)$ & $4(1.9)$ \\
\hline & $18-24.9 \mathrm{~kg} / \mathrm{m}^{2}$ & $65(40.6)$ & $28(50.9)$ & $93(43.3)$ \\
\hline & $25.0-29.9 \mathrm{~kg} / \mathrm{m}^{2}$ & $52(32.5)$ & $18(32.7)$ & $70(32.6)$ \\
\hline & $\geq 30 \mathrm{~kg} / \mathrm{m}^{2}$ & $40(25.0)$ & $8(14.5)$ & $48(22.3)$ \\
\hline \multirow{4}{*}{$\mathrm{CD}^{+} \mathrm{T}$ cell count* } & Mean \pm SD & $425.4(299.8)$ & $411(222.5)$ & $421.5(279.9)$ \\
\hline & $<200$ cells $\backslash \mu 1$ & $21(24.1)$ & $6(18.2)$ & $27(22.5)$ \\
\hline & 200-499 cells $\backslash \mu 1$ & $37(42.5)$ & $14(42.4)$ & $51(42.5)$ \\
\hline & $\geq 500$ cells $\backslash \mu 1$ & $29(33.3)$ & $13(39.4)$ & $42(35.0)$ \\
\hline \multirow{6}{*}{ Duration of HIV infection (month) } & Mean \pm SD & $65.4(42.7)$ & $18.7(26.0)$ & $53.4(44.1)$ \\
\hline & $<6$ months & $0(0.0)$ & $23(41.8)$ & $23(10.7)$ \\
\hline & 6-12 months & $26(16.3)$ & $15(27.3)$ & $41(19.1)$ \\
\hline & 13-24 months & $16(10.0)$ & $6(10.9)$ & $22(10.2)$ \\
\hline & $25-41$ months & $16(10.0)$ & $4(7.3)$ & $20(9.3)$ \\
\hline & $\geq 42$ months & $102(63.8)$ & $7(12.7)$ & $109(50.7)$ \\
\hline \multirow{4}{*}{ Marital Status } & Married & $57(35.6)$ & $25(45.5)$ & $82(38.5)$ \\
\hline & Single & $52(32.5)$ & $20(36.4)$ & $72(33.8)$ \\
\hline & Divorced & $8(5.0)$ & $5(9.1)$ & $13(6.1)$ \\
\hline & Widowed & $41(25.6)$ & $5(9.1)$ & $46(21.6)$ \\
\hline \multirow{3}{*}{ Occupation } & Salary employed & $17(10.6)$ & $7(12.7)$ & $24(11.2)$ \\
\hline & Self-employed & $114(71.3)$ & $41(74.5)$ & $155(72.1)$ \\
\hline & Unemployed & $29(18.1)$ & $7(12.7)$ & $36(16.7)$ \\
\hline \multirow{4}{*}{ Duration on HAART } & Mean \pm SD & $62.7(41.7)$ & - & - \\
\hline & $6-35$ months & $45(28.1)$ & - & - \\
\hline & $36-60$ months & $46(28.8)$ & - & - \\
\hline & $>60$ months & $69(43.1)$ & - & - \\
\hline
\end{tabular}

HAART-highly active antiretroviral therapy; BMI-body mass index; CD-cluster of differentiation; ${ }^{*}$-CD4 ${ }^{+} \mathrm{T}$ cell count available for 120 participants only.

untreated group. Use of HAART in the treatment of HIV posed a challenge to the cardiovascular risk profile of HIV infected persons compared to their untreated counterparts, nevertheless the treatment is still of paramount importance to limit the progression from HIV to AIDS defining conditions.

We have determined that HIV-infected persons had CVD risk factors notable for dyslipidemia. This is similarly to our study reported elsewhere [18]. The prevalence of dyslipidemia of $54.4 \%$ in this study was lower than that in a study among HIV patients in Dar es Salaam, Tanzania in which the prevalence of dyslipidemia was $76 \%$ [22]. The difference in prevalence with our study could be due to the fact that the Tanzanian study was only on the HAART naive patients while we used both HAART naive and HAART experienced patients. Our results are also lower than those reported from a Latin American HIV cohort of patients on HAART where the prevalence of dyslipidemia was $80 \%$ [23]. It is postulated that dyslipidemia is a result of the metabolic effects of the HIV virus itself and the metabolic effects of the HAART, thus increasing the risk of future cardiovascular events in HIV patients [15]. Apart from the effects of HAART and the HIV virus, dyslipidemia could also be explained by poor eating habits among the patients. A common practice in our local population is to encourage 
Table 2. Clinical and Biochemical characteristics of study participants.

\begin{tabular}{|c|c|c|c|c|}
\hline Parameters & All Mean $( \pm$ SD) & $\begin{array}{c}\text { HAART Naïve Mean }( \pm \text { SD) } \\
(n=55)\end{array}$ & $\begin{array}{l}\text { HAART Experienced } \\
\text { Mean }( \pm \text { SD })(n=160)\end{array}$ & p-Value \\
\hline \multicolumn{5}{|l|}{ Clinical Characteristics } \\
\hline SBP (mmHg) & $129.20 \pm 17.25$ & $124.35 \pm 15.30$ & $130.88 \pm 17.61$ & 0.0151 \\
\hline $\mathrm{DBP}(\mathrm{mmHg})$ & $82.31 \pm 13.08$ & $80.44 \pm 11.23$ & $82.96 \pm 13.63$ & 0.2187 \\
\hline BMI $\left(\mathrm{Kg} / \mathrm{m}^{2}\right)$ & $26.47 \pm 5.29$ & $25.09 \pm 4.54$ & $26.94 \pm 5.42$ & 0.0243 \\
\hline \multicolumn{5}{|l|}{ Biochemical Characteristics } \\
\hline $\mathrm{FBS}(\mathrm{mg} / \mathrm{dL})$ & $79.75 \pm 16.92$ & $86.64 \pm 17.39$ & $77.38 \pm 16.14$ & 0.0004 \\
\hline $\mathrm{TG}(\mathrm{mg} / \mathrm{dL})$ & $112.31 \pm 58.61$ & $97.69 \pm 55.93$ & $117.33 \pm 58.83$ & 0.0317 \\
\hline $\mathrm{TC}(\mathrm{mg} / \mathrm{dL})$ & $192.64 \pm 70.54$ & $147.65 \pm 44.55$ & $208.11 \pm 71.30$ & $<0.0001$ \\
\hline HDL-c (mg/dL) & $65.24 \pm 27.55$ & $61.16 \pm 26.24$ & $66.64 \pm 27.94$ & 0.2040 \\
\hline LDL-c (mg/dL) & $104.55 \pm 66.49$ & $67.09 \pm 42.22$ & $117.43 \pm 67.55$ & $<0.0001$ \\
\hline TC/HDL-c Cholesterol $\geq 5$ & $3.50 \pm 2.39$ & $2.84 \pm 1.68$ & $3.73 \pm 2.55$ & 0.0169 \\
\hline
\end{tabular}

SBP-Systolic blood pressure; DBP-Diastolic blood pressure; BMI-Body mass index; FBS-Fasting blood sugar; TG-Triglyceride; TC-Total cholesterol; HDL-c-High density lipoprotein cholesterol; LDL-c-Low density lipoprotein cholesterol.

Table 3. Proportion of cardiovascular disease risk factors in the two groups.

\begin{tabular}{|c|c|c|c|c|c|c|}
\hline Risk factor for CVD & $\begin{array}{l}\text { Overall } \\
\text { Prevalence } \\
\text { No }(\%)\end{array}$ & $\begin{array}{c}\text { Prevalence in HAART } \\
\text { Treated Group }(n=160) \\
\text { No }(\%)\end{array}$ & $\begin{array}{c}\text { Prevalence in HAART-Naïve } \\
\text { Group }(\mathbf{n}=55) \\
\text { No }(\%)\end{array}$ & OR & $95 \% \mathrm{CI}$ & p-Value \\
\hline Hypercholesterolemia & $86(40.0)$ & $80(50.0)$ & $6(10.9)$ & 8.17 & $3.31-20.14$ & $<0.001$ \\
\hline Hypertriglyceridemia & $42(19.5)$ & $33(20.6)$ & $9(16.4)$ & 1.33 & $0.59-2.99$ & 0.493 \\
\hline Increased LDL-c & $63(29.3)$ & $58(36.3)$ & $5(9.1)$ & 5.69 & $2.15-15.06$ & $<0.001$ \\
\hline Decreased HDL-c & $31(14.4)$ & $23(14.4)$ & $8(14.5)$ & 0.99 & $0.41-2.35$ & 0.975 \\
\hline Diabetes Mellitus & $5(2.33)$ & $3(1.9)$ & $2(3.6)$ & 0.51 & $0.08-3.11$ & 0.463 \\
\hline Obesity & $48(22.3)$ & $40(25.0)$ & $8(14.5)$ & 1.96 & $0.85-4.49$ & 0.113 \\
\hline Hypertension & $55(25.6)$ & $47(29.4)$ & $8(14.5)$ & 2.4 & $1.07-5.57$ & 0.033 \\
\hline Alcohol excess & $42(19.5)$ & $28(17.5)$ & $14(25.5)$ & 0.62 & $0.30-1.29$ & 0.202 \\
\hline Smoking & $4(1.9)$ & $3(1.9)$ & $1(1.8)$ & 0.97 & $0.10-9.51$ & 0.979 \\
\hline Family History & $80(37.2)$ & $67(41.9)$ & $13(23.6)$ & 2.32 & $1.16-4.67$ & 0.017 \\
\hline
\end{tabular}

OR-Odd ratio; CI-Confidence interval; HAART-Highly Active Antiretroviral Therapy; CVD- Cardiovascular disease; LDL-c-Low density lipoprotein cholesterol; HDL-c-High density lipoprotein cholesterol.

HIV patients to 'over-feed' on rich foodstuff so that they maintain their weight and improve immunity. In the past "Thin persons" were easily identified by society as being HIV infected and the associated social stigma. Thus HIV patients strive to get nutritional support and use food supplements. This may lead to overweight and dyslipidemia.

The prevalence of hypercholesterolemia in this study is higher than that reported in Tanzania by Swai and colleagues [24] in a general multiregional survey. However, our study was from a specific group of HIV infected patients. It is possible that a factor related to HIV disease and its treatment is responsible for increased hypercholesterolemia. However, there are suggestions that the magnitude of HIV infection and its treatment induced lipid derangements could vary across populations and settings. The prevalence of hypercholesterolemia in this study is similar to that reported by Yone and colleagues [17] in Yaounde, Cameroon among HIV patients who were on HAART and those not on HAART. The similarity with our study suggests an additional effect of HAART in the causation of hypercholesterolemia in HIV infected individuals.

The prevalence of hypertriglyceridemia in our study was $19.5 \%$ with males more affected than females although without any significant difference $(25.9 \%$ and $17.4 \%$ respectively, $\mathrm{P}=0.1710$ ). The pattern is similar to that which was reported in South African HIV patients in which more HIV males had hypertriglyceridemia than females [25]. Our prevalence was however lower than that reported by Armstrong and colleagues among HIV HAART naive patients [18]. High triglycerides levels in HIV patients has been postulated to be due to inflammation with subsequent 
Table 4. Proportion of cardiovascular disease risk factors by gender.

\begin{tabular}{|c|c|c|c|c|}
\hline Risk Factor for CVD & $\begin{array}{c}\text { Overall Prevalence } \\
\text { No (\%) }\end{array}$ & $\begin{array}{c}\text { Prevalence in Males } \\
(\mathbf{n = 5 4 ) ~ N o ( \% )}\end{array}$ & $\begin{array}{c}\text { Prevalence in Females } \\
(\mathbf{n = 1 6 1 )} \text { No (\%) }\end{array}$ & p-Value \\
\hline \hline Hypercholesterolemia & $86(40.0)$ & $13(24.1)$ & $73(45.3)$ & 0.0058 \\
\hline Hypertriglyceridemia & $42(19.5)$ & $14(25.9)$ & $28(17.4)$ & 0.1710 \\
\hline Increased LDL-c & $63(29.3)$ & $12(22.2)$ & $51(31.7)$ & 0.1865 \\
\hline Decreased HDL-c & $31(14.1)$ & $13(24.1)$ & $18(11.2)$ & 0.0196 \\
\hline Diabetes Mellitus & $5(2.3)$ & $4(7.4)$ & $1(0.6)$ & 0.0192 \\
\hline Obesity & $48(22.3)$ & $4(7.4)$ & $44(27.3)$ & 0.0043 \\
\hline Hypertension & $55(25.6)$ & $20(37.0)$ & $35(21.7)$ & 0.0404 \\
\hline Alcohol excess & $42(19.5)$ & $22(40.7)$ & $20(12.4)$ & $<0.0001$ \\
\hline Smoking & $4(1.9)$ & $4(7.4)$ & $0(0.0)$ & 0.0037 \\
\hline Family History & $80(37.2)$ & $19(35.2)$ & $61(37.9)$ & 0.8470 \\
\hline
\end{tabular}

CVD- Cardiovascular disease; LDL-c-Low density lipoprotein cholesterol; HDL-c-High density lipoprotein cholesterol.

Table 5. Cardiovascular disease risk factors and duration of HAART use $(\mathrm{N}=157)$.

\begin{tabular}{|c|c|c|c|c|c|}
\hline Duration on HAART & No (\%) & Risk Factor for CVD & OR & $95 \%$ CI & p-Value \\
\hline \multicolumn{6}{|l|}{ Hypercholesterolemia } \\
\hline 6-35 months* & $45(28.13)$ & $14(31.1)$ & 1.00 & - & - \\
\hline $36-60$ months & $46(28.75)$ & $24(52.2)$ & 2.42 & $1.03-5.69$ & 0.043 \\
\hline$>60$ months & $69(43.13)$ & $42(60.9)$ & 3.44 & $1.56-7.63$ & 0.002 \\
\hline \multicolumn{6}{|l|}{ Hypertriglyceridemia } \\
\hline 6-35 months* & $45(28.13)$ & $6(13.3)$ & 1.00 & - & - \\
\hline $36-60$ months & $46(28.75)$ & $7(15.2)$ & 1.17 & $0.36-3.79$ & 0.797 \\
\hline$>60$ months & $69(43.13)$ & $20(29.0)$ & 2.65 & $0.97-7.24$ & 0.057 \\
\hline \multicolumn{6}{|l|}{ Increased LDL-c } \\
\hline 6-35 months* & $45(28.13)$ & $11(24.4)$ & 1.00 & - & - \\
\hline $36-60$ months & $46(28.75)$ & $15(32.6)$ & 1.50 & $0.60-3.74$ & 0.510 \\
\hline$>60$ months & $69(43.13)$ & $32(46.4)$ & 2.44 & $1.17-6.12$ & 0.020 \\
\hline \multicolumn{6}{|l|}{ Decreased HDL-c } \\
\hline 6-35 months* & $45(28.13)$ & $6(13.3)$ & 1.00 & - & - \\
\hline $36-60$ months & $46(28.75)$ & $5(10.9)$ & 0.79 & $0.22-2.81$ & 0.719 \\
\hline$>60$ months & $69(43.13)$ & $12(17.4)$ & 1.37 & $0.47-3.95$ & 0.562 \\
\hline \multicolumn{6}{|l|}{ Diabetes Mellitus } \\
\hline 6-35 months* & $45(28.13)$ & $2(4.4)$ & 1.00 & - & - \\
\hline $36-60$ months & $46(28.75)$ & $0(0.0)$ & NA & NA & NA \\
\hline$>60$ months & $69(43.13)$ & $1(1.4)$ & 0.32 & $0.03-3.59$ & 0.353 \\
\hline \multicolumn{6}{|l|}{ Obesity } \\
\hline 6-35 months* & $45(28.13)$ & $6(13.3)$ & 1.00 & - & - \\
\hline $36-60$ months & $46(28.75)$ & 11(23.9) & 2.04 & $0.68-6.10$ & 0.201 \\
\hline$>60$ months & $69(43.13)$ & $23(33.3)$ & 3.25 & $1.20-8.79$ & 0.020 \\
\hline \multicolumn{6}{|l|}{ Hypertension } \\
\hline 6-35 months* & $45(28.13)$ & $11(24.4)$ & 1.00 & - & - \\
\hline $36-60$ months & $46(28.75)$ & $15(32.6)$ & 1.50 & $0.60-3.74$ & 0.390 \\
\hline$>60$ months & $69(43.13)$ & $21(30.4)$ & 1.35 & $0.58-3.17$ & 0.487 \\
\hline
\end{tabular}

*-Reference group; OR-Odd ratio; CI-Confidence interval; HAART-Highly Active Antiretroviral Therapy; CVD- Cardiovascular disease; LDL-c-Low density lipoprotein cholesterol; HDL-c-High density lipoprotein cholesterol.

cytokines release and decreased hepatic clearance related to a role of apolipoprotein E [26].
The prevalence of decreased HDL-c in this study was lower than the South Africa HIV cohort where it was 
reported to be high [25]. HDL-c is a cholesterol scavenger, picking up excess cholesterol from the blood and taking it back to the liver. The lower the HDL-c levels, the more the risk of hypercholesterolemia and hence increased CVD risk. Decreased levels of HDL-c occur at an early stage of HIV infection. Low HDL-c is a well-recognized independent risk factor for adverse cardiovascular outcomes and this has even been shown to be true in HIV-infected individuals, irrespective of other risk factors [27].

Elevated LDL-c occurred in $29.3 \%$ of our study participants with more females affected than males $(31.7 \%$ and $22.2 \%$ respectively, $\mathrm{P}=0.1865$ ). This prevalence is lower than that reported by Armstrong and colleagues in Tanzania among HIV patients who were not on HAART (67\%) [18]. The results are higher than that reported in a Latin American study in which it was found to be $25 \%$ [28]. The results from all these studies call for a need for interventions to prevent premature CVD among HIV patients.

The prevalence of diabetes mellitus in the present study was $2.3 \%$. This was significantly higher in males than females participants $(7.4 \%$ and $0.6 \%, \mathrm{P}=0.0192)$. Diabetes mellitus in HIV patients is due to genetic factors or the toxic effects of elevated circulating lipids (beta cell lipotoxicity) as the consequences of lipodystrophy or could be drug induced [29].

In the present study women were found to be more obese than males $(27.3 \%$ and $7.4 \%, p=0.0043)$. This study was similar to the study conducted among HIV patients in Western Kenya in which the prevalence of obesity among female HIV patients was higher than in HIV positive males [30]. Obesity in this population could be explained in part by a factor related to stigma; the tendency from the community is to encourage the HIV patients to be obese as loss of weight could easily reveal their status.

Data on the prevalence of hypertension in HIV patients are limited. A few studies have reported an increased prevalence of hypertension in ART treated patients [15,31]. In our study, the associations between antiretroviral drug regimens and hypertension in univariable logistic models were statistically significantly different. Thus, our data supports a concern that HIV treatment is likely to induce hypertension. Gazzaruso and colleagues [32] found no association between ART and hypertension, but their study only examined exposure to NRTIs and PIs and not the duration of treatment exposure.

Diabetes mellitus was more prevalent among HAARTnaïve than HAART experienced participants. These results are not in keeping with the major trial DAD study [33] and that of Manuthu and colleagues [34] in which diabetes mellitus was found to be more prevalent among HIV patients on HAART compared to HAART naive. PI and NRTI therapy are implicated in the causation of diabetes mellitus among HIV patients. Mechanisms suggested include PIs directly inhibit the uptake of glucose by insulin-sensitive tissues, such as fat and skeletal muscle, and by selective inhibition of the glucose transporter Glut4 [29]. More research has been published from developed countries dealing with both the prevalence and incidence of diabetes [35-37]. Most of these studies report prevalence and/or incidence rates higher than that observed in the general population [35], while others report similar [36], or even lower [37], figures. Even though conventional risk factors have been confirmed in this population, ART exposure is not unanimously recognized as a factor associated with diabetes $[36,38]$.

\section{CONCLUSION}

Our findings highlight the need to aggressively assess and manage risk factors for CVD, particularly derangement of lipids, in HIV-infected populations. With increasing years of survival and living with HIV infection, many patients will transit into age groups with greater prevalence of CVD and other medical conditions, which impose risk of CVD. Further prolonging survival among HIV-infected persons will increasingly be influenced by non-AIDS-defining conditions. Thus, there is need for $\mathrm{CV}$ risk factors assessment before initiation of HAART followed by periodic monitoring while on the treatment. This will ensure prompt detection and management of $\mathrm{CV}$ risk factors and the prevention of cardiovascular events.

\section{AUTHORS' CONTRIBUTION}

NDS participated in the conception, oversaw data collection and supervised the work, participated in data analysis, drafted the manuscript and substantially revised the manuscript for academic content; ANJC participated in design, data interpretation and drafting of the manuscript. NAL participated in data collection, data analysis, conducted literature search and review, read and corrected the manuscript. TEA participated in the conception, designed the study, conducted the study, data analysis/interpretation and drafting of manuscript; KOD participated in data analysis, conducted literature search and review, read and corrected the manuscript, ACW performed the analyses and interpretation, conducted the literature search and review, and wrote the first draft; NNM oversaw data collection and supervised the work and substantially revised the manuscript for academic content. All authors read and approved the final copy of the manuscript.

\section{ABBREVIATIONS}

$$
\begin{array}{ll}
\text { 3TC } & =\text { Lamivudine } \\
\mathrm{ART} & =\text { Antiretroviral Therapy } \\
\mathrm{AZT} & =\text { Zidovudine } \\
\mathrm{BMI} & =\text { Body Mass Index } \\
\mathrm{CVD} & =\text { Cardiovascular disease } \\
\mathrm{EFV} & =\text { Efavirenz } \\
\mathrm{HAART} & =\text { Highly Active Antiretroviral Therapy } \\
\mathrm{HDL}-\mathrm{c} & =\text { High Density Lipoproteins cholesterol } \\
\text { LDL-c } & =\text { Low Density Lipoproteins cholesterol } \\
\text { LPV/r } & =\text { Lapinavir } \\
\text { NNRTI } & =\text { Non-Nucleoside Reverse Transcriptase } \\
& \text { Inhibitor } \\
\text { NRTI } & \text { Nucleoside Reverse Transcriptase Inhibitor }
\end{array}
$$




$$
\begin{array}{ll}
\mathrm{NVP} & =\text { Nevirapine } \\
\mathrm{PI} & =\text { Protease Inhibitors } \\
\mathrm{PLWHA} & =\text { People Living with HIV/AIDS } \\
\mathrm{TC} & =\text { Total cholesterol } \\
\mathrm{TDF} & =\text { Tenofovir } \\
\mathrm{TG} & =\text { Triglycerides }
\end{array}
$$

\section{CONFLICT OF INTEREST}

The authors declare that they have no conflict of interest.

\section{ACKNOWLEDGEMENTS}

We are grateful to the Directors and staff of Buea and Limbe Regional Hospitals for the assistance in data collection. We are also thankful to all the patients who participated in the study.

\section{REFERENCES}

[1] Global Report: UNAIDS report on the global AIDS epidemic. http://www.unaids.org/globalreport/global_report. [Accessed: December 18, 2013].

[2] Nsagha DS, Bissek ACZK, Nsagha SM, et al. The burden of orphans and vulnerable children due to HIV/AIDS in Cameroon. Open AIDS J 2012; 6: 245-58.

[3] Global update on HIV treatment 2013: results, impact and opportunities. http://www.who.int/hiv [Accessed: February 10, 2014.]

[4] Grinsztejn B, Luz PM, Pacheco AG, et al. Changing mortality profile among HIV-infected patients in Rio de Janeiro, Brazil: Shifting from AIDS to non-AIDS related conditions in the HAART era. PLoS One 2013; 8(4): e59768.

[5] Pacheco AG, Tuboi SH, Faulhaber JC, Harrison LH, Schechter M. Increase in non-AIDS related conditions as causes of death among HIV-infected individuals in the HAART era in Brazil. PLoS One 2008; 3(1): e1531.

[6] Sterne JAC, Hernan MA, Ledergerber B. and the Swiss HIV Cohort Study. Long-term effectiveness of potent antiretroviral therapy in preventing AIDS and death: A prospective cohort study. Lancet 2005; 366: 378-84.

[7] Carr A, Samaras K, Burton S, Law M, Freund J, Chisholm DJ. A syndrome of peripheral lipodystrophy, hyperlipidaemia, and insulin resistance in patients receiving HIV protease inhibitors. AIDS 1998; 12: 51-8.

[8] Jerico C, Knobel H, Montero M, Ordoñez-Llanos J, Guelar A, Gimeno JL. Metabolic syndrome among HIV-infected patients: Prevalence, characteristics, and related factors. Diabetes Care 2005; 28:132-7.

[9] Hadigan C, Meigs JB, Corcoran C, Rietschel P, Piecuch S, Basgoz N. Metabolic abnormalities and cardiovascular disease risk factors in adults with human immunodeficiency virus infection and lipodystropy. Clin Infect Dis 2001; 32: 130-9.

[10] Mondy K, Overton ET, Grabb J, et al. Metabolic syndrome in HIVinfected patients from an urban, mid-western US outpatient population. Clin Infect Dis 2007; 44: 726-34.

[11] McDonald CL, Kaltman JR. Cardiovascular disease in adult and pediatric HIV/AIDS. J Am Coll Cardiol 2009; 54: 1185-8.

[12] Grunfeld C, Delaney JAC, Wanke C, et al. Preclinical atherosclerosis due to HIV infection: carotid intima-medial thickness measurements from the FRAM study. AIDS 2009; 23: 1841-9.

[13] Guaraldi G, Stentarelli C, Zona S, et al. Lipodystrophy and antiretroviral therapy as predictors of sub-clinical atherosclerosis in human immunodeficiency virus infected subjects. Atherosclerosis 2010; 208: 222-7.
[14] Muronya W, Sanga E, Talama G, Kumwenda JJ, van Oosterhout JJ. Cardiovascular risk factors in adult Malawians on long-term antiretroviral therapy. Trans R Soc Trop Med Hyg 2011; 105(11): 644-9.

[15] Bloomfield GS, Hogan JW, Keter A, et al. Hypertension and obesity as cardiovascular risk factors among HIV seropositive patients in Western Kenya. PLoS One 2011; 6(7): e22288.

[16] Bekolo CE, Nguena MB, Ewane L, Bekuole PS, Kolo B. The lipid profile of HIV-infected patients receiving antiretroviral therapy in a rural Cameroonian population. BMC Public Health 2014; 14: 236.

[17] Yone PEW, Betyoumin AF, Kengne AP, Folefack FJK, Ngogang J. First-line antiretroviral therapy and dyslipidemia in people living with HIV-1 in Cameroon. AIDS Res Therapy 2011; 8: 33.

[18] Nsagha DS, Weledji EP, Assob NJC, et al. Highly active antiretroviral therapy and dyslipidemia in people living with HIV/AIDS in Fako division, south west region of Cameroon. BMC Cardiovasc Disord 2015; 15: 95. doi: 10.1186/s12872-015-0090-5.

[19] Physical status: The use and interpretation of anthropometry. Report of a WHO Expert Committee. World Health Organ Tech Rep Ser 1995; 854: 1-452.

[20] Report of the expert committee on the diagnosis and classification of diabetes mellitus. Diabetes Care 1997; 20:1183-97.

[21] Expert panel on detection and treatment of high blood cholesterol in adults: executive summary of the third report of the national cholesterol education program (NCEP) expert panel on detection, evaluation, and treatment of high blood cholesterol, in: adults (adult treatment panel III). JAMA 2001; 285: 2486-97.

[22] Armstrong CLE, Okuma J, Spiegelman D, et al. Dyslipidemia in an HIV-positive antiretroviral treatment-naïve population in Dar Es Salaam, Tanzania. J Acquir Immune Defic Syndr 2011; 57(2): 1415 .

[23] Leite R. Metabolic profile and cardiovascular risk factors among Latin American HIV-infected patients receiving HAART. Braz J Infect Dis 2010; 14(2): 158-66

[24] Swai AB, McLarty DG, Kitange HM, et al. Low prevalence of risk factors for coronary heart diseases in rural Tanzania. Int Epidemiol 1993; 22(4): 651-9.

[25] Julius HBD, Ricci E, Wing J, Basu JK. The burden of metabolic diseases amongst HIV positive patients on HAART attending The Johannesburg Hospital. Curr HIV Res 2011; 9(4): 247-52.

[26] Grunfeld C, Pang M, Doerrler W, Shigenaga JK, Jensen P, Feingold KR. Lipids, lipoproteins, triglyceride clearance, and cytokines in human immunodeficiency virus infection and the acquired immunodeficiency syndrome. J Clin Endocrinol Metab 1992; 74(5):1045-52.

[27] Basa CB, de Otajaza CP, Montel DC, Montel JCC, Aparicio MS, Del-Romero Guerororo J. Lipid profile in untreated HIV positive patients. HIV infection: cardiovascular risk factor? An Med Interna 2007; 24(4): 160-7.

[28] Grunfeld C. Dyslipidemia and its Treatment in HIV Infection. Top HIV Med 2010; 18: 112-8.

[29] McGarry JD. Dysregulation of fatty acid metabolism in the etiology of type 2 diabetes. J Diabetes 2002; 51: 7-18.

[30] Gerald SB, Joseph WH, Alfred K, et al. Hypertension and obesity as cardiovascular risk factors among HIV seropositive patients in western Kenya. Plos One 2011; 6(7): 14.

[31] Cattelan AM, Trevenzoli M, Sasset L, Rinaldi L, Balasso V, Cadrobbi P. Indinavir and systemic hypertension. AIDS 2001; 15 : 805-7.

[32] Gazzaruso CBR, Garzaniti A, Giordanetti S, Fratino P, Sacchi P, Hypertension among HIV patients: Prevalence and relationships to insulin resistance and metabolic syndrome. J Hypertens 2003; 21: 1377-82.

[33] Manuthu EM, Joshi MD, Lule GN, Karari E. Prevalence of dyslipidemia and dysglycaemia in HIV infected patients journal. East Afr Med J 2008; 85(1): 10-17.

[34] Friis-Møller NW, Reiss VP, Thièbaut RKO. Cardiovascular disease risk factors in HIV patients-association with antiretroviral therapy. Results from the DAD study. AIDS 2003; 17: 1179-93.

[35] Bedimo R, Westfall AO, Mugavero M, Drechsler H, Khanna N, Saag M. Hepatitis $C$ virus coinfection and the risk of cardiovascular disease among HIV-infected patients. HIV Med 2010; 11(7): 462-8. 
[36] Howard AA, Floris-Moore M, Lo Y, Arnsten JH, Fleischer N, Klein RS. Disorders of glucose metabolism among HIV-infected women. Clin Infec Dis 2005; 40(10): 1492-9.

[37] Cahn P, Leite O, Rosales A, et al. Metabolic profile and cardiovascular risk factors among Latin American HIV-infected patients receiving HAART. Braz J Infec Dis 2010; 14(2): 158-66.
[38] Wand H, Calmy A, Carey DL, et al. Metabolic syndrome, cardiovascular disease and type 2 diabetes mellitus after initiation of antiretroviral therapy in HIV infection. AIDS 2007; 21(18): 2445-53.

(C) Nsagha et al.; Licensee Bentham Open.

This is an open access article licensed under the terms of the Creative Commons Attribution Non-Commercial License (http://creativecommons.org/licenses/by-nc/

3.0/) which permits unrestricted, non-commercial use, distribution and reproduction in any medium, provided the work is properly cited. 